\title{
EFEKTIFITAS METODE SIKAT GIGI VERTIKAL DAN HORIZONTAL TERHADAP PENURUNAN INDEKS PLAK PADA ANAK USIA 9-11 TAHUN DI MI DDI SEPPANGE DI DESA TUNGKE KECAMATAN BENGO, KABUPATEN BONE, SULAWESI SELATAN
}

\author{
Munadirah, Muhammad Saleh
}

\begin{abstract}
ABSTRAK
Pembersihan gigi yang kurang baik dapat menyebabkan terjadinya akumulasi plak. Salah satu cara menghilangkan plak yaitu dengan menyikat gigi. Plak adalah lapisan tipis, tidak berwarna, mengandung kumpulan bakteri, melekat pada permukaan gigi dan selalu terbentuk di dalam mulut dan bila bercampur dengan gula yang ada dalam makanan akan membentuk asam. Penentuan Sampel dalam penelitian ini yaitu menggunakan sampel random sampling dengan mencari 40 siswa siswi MI DDI Seppange di Desa Tungke Kecamatan Bengo Kabupaten Bone kemudian membaginya menjadi 2 kelompok yaitu 20 siswa dengan metode menyikat gigi secara vertkal dan 20 siswa dengan metode menyikat gigi secara horizontal yang diberi penyuluhan tentang kesehatan gigi dan mulut.
\end{abstract}

Kata Kunci: Metode Sikat Gigi Vertikal dan Horisontal, Indeks Plak

\section{PENDAHULUAN}

Kesehatan gigi dan mulut dasar di Indonesia masih perlu mendapat perhatian khusus dari tenaga kesehatan gigi dan mulut. Hal in disebabkan karena sebagian besar masyarakat $\mathrm{d}$ Indonesia mengabaikan kesehatan gigi dan mulut mereka sendiri, termasuk anak usia sekolah dasar. Kelompok anak usia sekolah dasar merupakan kelompok yang rentan terhadap penyakit gigi dan mulut sehingga perlu diperhatikan dan dicegah secara baik dan benar. pada anak berusia 10-14 tahun yang memiliki masalah gigi dan mulut di Indonesia. Kondisi ini dapat berpengaruh pada derajat kesehatan mereka dalam proses tumbuh kembang bahkan masa depan mereka.

Selain peran orang tua dalam membimbing, memberikan pengertian dan mengingatkan anak untuk menjaga kesehatan gigi dan mulut, perlu dilakukan penyuluhan kesehatan gigi dan mulut oleh tenaga kesehatan. Penyuluhan kesehatan gigi dan mulut merupakan salah satu upaya untuk mencegah masalah kesehatan gigi dan mulut, dengan tercapainya tingkat kesehatan gigi yang lebih baik di masa mendatang. Usia anak sekolah dasar ialah saat yang tepat dimana seorang anak dilatih kemampuannya untuk menjaga dan memelihara kebersihan gigi dan mulut yaitu melalui cara menyikat gigi yang benar.
Pembersihan gigi yang kurang baik dapat menyebabkan terjadinya akumulasi plak. Salah satu cara menghilangkan plak yaitu dengan menyikat gigi. Plak adalah lapisan tipis, tidak berwarna, mengandung kumpulan bakteri, melekat pada permukaan gigi dan selalu terbentuk di dalam mulut dan bila bercampur dengan gula yang ada dalam makanan akan membentuk asam. Plak akan terlihat satu sampai dua hari apabila tidak ada langkah-langkah pembersihan mulut. Berdasarkan penelitian yang dilakukan llyas tentang efek penyuluhan metode demonstrasi menyikat gigi terhadap penurunan indeks plak gigi pada siswa sekolah dasar menyatakan bahwa terjadi penurunan nilai plak.

Berdasarkan latar belakang di atas, peneliti tertarik untuk melakukan penelitian sekaligus memberikan penyuluhan mengenai cara menyikat gigi pada siswa MI DDI Seppange. Penyuluhan tentang cara menyikat gigi belum pernah dilakukan di sekolah dasar ini, dan belum pernah ada tenaga kesehatan yang memberikan sosialisasi berupa penyuluhan cara menyikat gigi, sehingga penulis tertarik untuk melihat pengaruh penyuluhan tentang cara menyikat gigi terhadap indeks plak. 


\section{METODE PENELITIAN}

Jenis penelitian yang digunakan adalah observational analitik dengan pendekatan cross sectional yaitu melakukan pemeriksaan langsung dengan melihat penelitian yang dilakukan sekali dan dalam yg bersamaan.

\section{HASIL PENELITIAN DAN PEMBAHASAN}

Hasil penelitian yang dilakukan pada siswa di MI DDI Seppange Di Desa Tungke
Kecamatan Bengo Kabupaten Bone yang dilaksanakan pada tanggal 5 juni 2015 dengan jumlah sampel sebanyak 40 orang terdiri dari 20 orang siswa menggunakan teknik menyikat gigi secara vertikal dan 20 orang siswa menggunakan teknik menyikat gigi secara horizontal. kemudian berdasarkan pemeriksaan secara langsung kepada responden, maka diperoleh data tabel sebagai berikut:

Tabel 1 Distribusi Responden Berdasarkan Usia dan Jenis Kelamin

\begin{tabular}{|c|c|c|c|}
\hline \multirow{2}{*}{ Umur } & \multicolumn{2}{|c|}{ Jenis Kelamin } & \multirow{2}{*}{ Jumlah } \\
\cline { 2 - 3 } & Perempuan & Laki-laki & \\
\hline 9 Tahun & 6 & 3 & 9 \\
\hline 10 Tahun & 4 & 7 & 20 \\
\hline 11 Tahun & 9 & 11 & $\mathbf{4 0}$ \\
\hline Total & $\mathbf{1 9}$ & $\mathbf{2 1}$ & \\
\hline
\end{tabular}

Dari tabel di atas menunjukkan bahwa terdapat 40 responden yang dilakukan pemeriksaan. Pada usia 9 tahun terdapat 9 orang yang terdiri dari 6 perempuan 3 laki-laki, untuk usia 10 tahun terdapat 11 orang yang terdiri dari 4 perempuan 7 laki-laki,untuk usia 11 tahun terdapat 20 orang yang terdiri dari 9 perempuan 11 laki-laki.

Tabel 2. Distribusi Nilai Indeks Plak Sebelum Penyuluhan Sikat Gigi dengan Teknik Vertikal dan Horizontal.

\begin{tabular}{|c|c|c|c|c|c|c|c|c|}
\hline \multirow{3}{*}{$\begin{array}{c}\text { Teknik Sikat } \\
\text { Gigi }\end{array}$} & \multicolumn{6}{|c|}{ Kriteria Indeks Plak } & \multirow{3}{*}{$\mathrm{N}$} & \multirow{3}{*}{$\begin{array}{c}\text { Jumlah } \\
\text { Indeks Plak }\end{array}$} \\
\hline & \multirow{2}{*}{\multicolumn{2}{|c|}{$\frac{\text { Baik }}{N}$}} & \multirow{2}{*}{\multicolumn{2}{|c|}{$\frac{\text { Sedang }}{\mathrm{N}}$}} & \multirow{2}{*}{\multicolumn{2}{|c|}{$\frac{\text { Buruk }}{\mathrm{N}}$}} & & \\
\hline & & & & & & & & \\
\hline Vertikal & 0 & 0 & 11 & 20,4 & 9 & 19,5 & 20 & 39,9 \\
\hline Horizontal & 0 & 0 & 19 & 32,4 & 1 & 2,1 & 20 & 34,5 \\
\hline
\end{tabular}

Dari tabel di atas sebelum penyuluhan sikat gigi dengan teknik yang berbeda. Dengan menujukkan bahwa untuk teknik vertikal dengan jumlah siswa yang paling banyak terdapat pada kriteria sedang yaitu 11 siswa dengan indeks plak 20,4,untuk kriteria buruk terdapat 9 siswa dengan indeks plak
19,5 dan untuk kriteria baik tidak terdapat pada siswa. . Sedangkan Teknik horizontal jumlah siswa yang paling banyak terdapat pada kriteria sedang yaitu 19 siswa dengan indeks plak 32,4,untuk kriteria buruk yaitu 1 siswa dengan indeks plak 2,1 dan kriteria baik tidak terdapat pada siswa. 
Tabel 3. Distribusi Nilai Indeks Plak Setelah Penyuluhan Sikat Gigi dengan Teknik Vertikal dan Horizontal

\begin{tabular}{|c|c|c|c|c|c|c|c|}
\hline \multirow{3}{*}{$\begin{array}{c}\text { Teknik Sikat } \\
\text { Gigi }\end{array}$} & \multicolumn{6}{|c|}{ kriteria Indeks Plak } & \multirow{3}{*}{$\mathrm{N}$} \\
\hline & \multirow{2}{*}{\multicolumn{2}{|c|}{$\frac{\text { Baik }}{N}$}} & \multirow{2}{*}{\multicolumn{2}{|c|}{$\frac{\text { Sedang }}{\mathrm{N}}$}} & \multirow{2}{*}{\multicolumn{2}{|c|}{$\begin{array}{c}\text { Buruk } \\
\mathrm{N}\end{array}$}} & \\
\hline & & & & & & & \\
\hline Vertikal & 1 & 1,0 & 19 & 24,4 & 0 & 0 & 20 \\
\hline Horizontal & 1 & 1,0 & 19 & 26,1 & 0 & 0 & 20 \\
\hline
\end{tabular}

Dari tabel di atas dapat dilihat bahwa teknik menyikat gigi secara vertikal dan horizontal terdapat indeks plak, dengan kriteria baik sebanyak 2 siswa, kriteria sedang sebanyak 38 siswa dan kriteria buruk tidak terdapat siswa.

Tabel 4. Distribusi Nilai Indeks Plak Sebelum dan Sesudah Penyuluhan Sikat Gigi dengan Teknik Vertikal dan Horizontal

\begin{tabular}{|l|c|c|c|c|c|c|}
\hline \multirow{2}{*}{$\begin{array}{l}\text { Teknik } \\
\text { Menyikat Gigi }\end{array}$} & \multicolumn{5}{|c|}{ Kriteria Indeks Plak } \\
\cline { 2 - 7 } & \multicolumn{3}{|c|}{ Sebelum } & \multicolumn{3}{c|}{ Sesudah } \\
\cline { 2 - 7 } & Baik & Sedang & Buruk & Baik & Sedang & Buruk \\
\hline Vertikal & 0 & 11 & 9 & 1 & 19 & 0 \\
\hline Horizontal & 0 & 19 & 1 & 1 & 19 & 0 \\
\hline
\end{tabular}

Dari tabel 4 di atas dapat dilihat bahwa teknik menyikat gigi secara vertikal dan horizontal sebelum dan sesudah dapat dilihat perbandingannya yaitu sebelum penyuluhan terdapat 20 siswa, dimana kriteria baik tidak terdapat pada siswa, sedangkan kriteria sedang 11 siswa dan kriteria buruk 9 siswa. Teknik horizontal sebelum penyuluhan terdapat 20 siswa dari kriteria baik 0,dari kriteria sedang 19 siswa sedangkan kriteria buruk 1 siswa dengan jumlah vertikal dan horisontal 40 responden.

\section{PEMBAHASAN}

Plak adalah suatu deposit lunak yang terdiri atas kumpulan bakteri yang berkembang biak diatas matriks dan melekat erat pada permukaan gigi bila seseorang mengabaikan kebersihan gigi dan mulutnya. Plak juga dianggap sebagai salah satu faktor penyebab lokal dalam berbagai penyakit gigi dan jaringan pendukungnya,plak dapat di bersihkan dengan cara menyikat gigi dan perlu diperhatikan dalam kehidupan sehari-hari salah satu cara efektif.

Vol. 18 No.1 Tahun 2019
Dengan menyikat gigi sebagian besar plak dapat disingkirkan atau dibersihkan menggunakan sikat gigi seperti gerakan dan arah gerakannya (Lindhe,1990,cit. Abiyono,2001

Pemeriksaan indeks plak sebelum dan sesudah penyuluhan dilakukan pada 40 responden dengan rentang usia 9-11 tahun, yang terdiri dari 19 anak perempuan dan 21 anak laki-laki. Adapun teknik menyikat gigi pada penelitian ini yang telah peneliti lakukan yaitu teknik menyikat gigi secara vertikal dan teknik menyikat gigi secara horizontal.

Sebelum penyuluhan dengan teknik vertikal indeks plak menunjukkan bahwa pada kriteria baik tidak terdapat pada siswa. Pada kriteria sedang terdapat 11 siswa yang memiliki jumlah indeks plak 20,4, sedangkan pada kriteria buruk terdapat 9 siswa yang memiliki jumlah indeks plak 19,9 dapat dilihat pada tebel 2. Di karenakan tingkat pengetahuan tentang teknik menyikat gigi yang baik dan benar masih kurang dan tidak terlalu diperhatikan oleh responden sehingga berpengaruh terhadap indeks plak kebersihan gigi pada anak. 
Sebelum penyuluhan dengan teknik horizontal dengan indeks plak menunjukkan bahwa pada kriteria baik tidak terdapat pada siswa. Untuk kriteria sedang terdapat 19 siswa yang memiliki jumlah indeks plak 32,4 , sedangkan pada kriteria buruk terdapat 1 siswa yang memiliki jumlah indeks plak 2,1 dapat dilihat pada tabel 2. Di karenakan tingkat pengetahuan tentang teknik menyikat gigi yang baik dan benar masih kurang dan tidak terlalu diperhatikan oleh responden sehingga berpengaruh terhadap indeks kebersihan gigi pada anak. Setelah penyuluhan indeks plak dengan teknik vertikal dan horizontal dapat dilihat pada tabel 3 dan setelah responden melakukan sikat gigi dengan teknik yang berbeda,dapat dilihat bahwa teknik vertikal lebih meningkat karena tidak terdapat kriteria buruk dimana kriteria sedang 19 siswa dengan jumlah indeks plak 24,4 dan untuk kriteria baik 1 dengan jumlah indeks plak 1,0. Sementara untuk teknik horizontal terdapat 19 siswa untuk kriteria sedang dengan jumlah indeks plak 26,1 dan kriteria baik untuk 1 siswa dengan jumlah indeks plak 1,0 dan untuk kriteria buruk tidak terdapat pada siswa. Dikarenakan responden telah mengetahui dan memperhatikan cara sikat gigi yang baik dan benar sehingga untuk kriteria buruk sudah berkurang.

\section{SIMPULAN DAN SARAN}

Simpulan

Berdasarkan hasil penelitian yang dilakukan pada usia 9-11 tahun di MI DDI Seppange di Desa Tungke Kecamatan Bengo Kabupaten Bone tentang efektifitas metode sikat gigi vertikal dan horizontal terhadap penurunan indeks plak dapat disimpulkan bahwa:

1. Metode sikat gigi vertikal lebih efektif dibanding metode sikat gigi horizontal.

2. Sebelum penyuluhan tentang sikat gigi dengan metode vertikal dan horizontal yaitu lebih tinggi indeks plak yang dimiliki oleh responden.
3. Sesudah sikat gigi dengan metode yang berbeda yaitu indeks plak yang dimiliki responden berkurang.

\section{Saran}

1. Diharapkan UKGS yang sudah ada dsekolah lebih diperhatikan dan diaplikasikan untuk semua murid agar kelak para siswa-siswi lebih menjaga kebersihan gigi dan mulutnya.

2. Sebaiknya bagi orang tua untuk memperhatinkan anak-anaknya cara menyikat gigi yang benar sejak dini untuk mengurangi timbulnya penyakit gigi dan mulut.

3. Bagi generasi selanjutnya yang akan melakukan penelitian dengan sampel yang sama, gunakan penyuluhan yang lebih baik agar dapat menjadi motivasi dalam menjaga kebersihan gigi dan mulut para anak atau siswa sekolah dasar.

\section{DAFTAR PUSTAKA}

1. Ayu Wirayuni,Kadek. 2003. Jurnal Kedokteran Gigi Mahasaraaswati. Bali: Plaque conrol

2. Andlaw Dan Roc. 1992. Perawatan Gigi Anak. Jakarta: Widiyia Medika

3. Hermina dan Vera. 2010. Dentika Dental Journal. Medan: issn.

4. Houwink dkk. 1993. Ilmu Kedokteran Gigi Pencegahan. Yogyakarta: Gajah Mada University pres.

5. Pratiwi Erlita 2013. Masalah dan Solusi penyakit Gigi Dan Mulut . Yogyakarta : Rapha Publishing.

6. Hiranya dkk 2009. Ilmu Pencegahan Penyakit Jaringan Keras Dan Jaringan Pendukung Gigi. Jakarta: EGC

7. Sumawawinata. 1992.Dasar-Dasar karies Penyakit Dan Penanggulangannya. Jakarta: EGC.

8. Yundali dan Aditya Warman.2012. Kesehatan Gigi dan mulut. Pustaka Bandung: Reka Cipta.

9. Yuwono Lilian.1991. Pencegahan Penyakit Mulut. Jakarta: Hipokrates. 